\title{
A Design of Business-Technology Alignment Consulting Framework
}

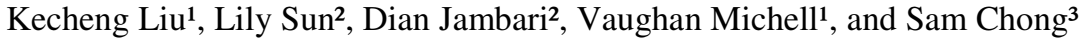 \\ ${ }^{1}$ Informatics Research Centre, University of Reading, PO Box 241, Whiteknights, \\ Reading, RG6 6WB, UK \\ k.liu@henley.reading.ac.uk, v.a.michell@reading.ac.uk \\ ${ }^{2}$ School of Systems Engineering, University of Reading, Whiteknights, Reading, Berkshire, \\ RG6 6AY, UK \\ \{lily.sun, j.dianindrayani\}@reading.ac.uk \\ ${ }^{3}$ CTO Emerging Solution Group, Cisco APAC, Capital Tower, \\ 168 Robinson Rd \#26-01 to \#29-01 Singapore \\ sachong@cisco.com
}

\begin{abstract}
Current work on applying scientific methods to capture the cultural values as requirements for business-IT alignment has been scarce, even though organisations acknowledge its significant impact. This paper introduces a Business-Technology Alignment Consulting Framework that adopts an Organisational Semiotics approach to capture cultural values from both formal norms and informal hidden social norms that can significantly impact the actual vs perceived alignment. A set of techniques in the framework are described for its use in conducting consulting analysis. Business Service Analysis is the core analysis that provides the holistic structure of the business services. Business Service Valuation calculates the service cultural values to complement the Business Service Analysis. Business Service Norms Analysis captures the business norms that govern the business service. A case study example is used to illustrate the analysis templates to holistically represent the business services. The significance of the consulting framework and future work are also discussed.
\end{abstract}

Keywords: business-technology alignment, consulting framework, sociotechnical approach, consulting requirements analysis, norm analysis.

\section{Introduction}

Organisations have acknowledged the importance of a well aligned business and IT to ensure competitiveness. However, achieving alignment is difficult due to challenges such as poor shared knowledge management [1], rigid alignment strategy constricting the ability to adapt to changes [2] and miscommunication due to "language" differences between the business and IT domain [3]. The failure to capture and account for social views and influences can affect alignment problems [4]. IT spending is an organisation's major investments. Increasingly complex and expensive IT deliveries [5],[6]directly impacts an organisation's business performance and has reigned as one of their top concerns [7]. The alignment quality is measured by 1) the value added by 
the business services to the enterprise to achieve their business goals, 2) the optimum "performance versus cost" of the IT capabilities to complement the value added business services. Therefore, a sensible alignment strategy between business and IT is essential to help organisations improve their financial efficiency particularly towards their IT investments. Organisations require a mechanism that can provide the mapping of the current business service with the "best fit" IT capabilities. They also need to be able to provide recommendations for the future IT strategy to assist in decision making for their IT investments, which inevitably improve the business service and IT applications alignment. However, before any alignment activities can be performed, a set of comprehensive and accurate requirements are needed to form a solid foundation to ensure well aligned business and IT. Business and technology consultants are facing challenges in articulating what IT applications are currently used for adding business value in an organisation. It is also difficult for consultants to recommend the future of those IT applications in relation to effective computing resources in the organisation. There are a number of factors contributing to these difficulties, 1) business environments have become complex and IT applications are deeply integrated with the business operations; 2) various IT applications serve different users for different purposes in their work; and 3) The socio-technical phenomenon impacts on business behavior towards IT applications. IT applications also add different benefits to the business performance and these benefits or values are normally perceived differently from a cultural perspective [8],[9]. Such multiple dimensional aspects can be described by complex business-IT alignment requirements which need to be captured by consultants. Well gathered and represented requirements enable the production of better analysis results for the current state of the business and IT alignment. It also helps the organisation in setting the future direction of the organisation to achieve their ultimate aims and objectives. Therefore, having the right requirements will ensure that the organisation will have the correct knowledge to establish a better alignment between their business and IT aspects [10],[11].

The Business-Technology Alignment Consulting Framework, therefore, has been developed to facilitate the analysis of business-IT alignment requirements in organisations. This framework enables consultants to establish a holistic view of the business situation and the IT applications supporting the business. The framework first defines whether a business operation is a core or supporting service. It then identifies and prioritises the future of the IT applications based on their support of these services and recommends, depending on the business service that the IT supports, if an IT application should be developed/upgraded with new functions to adequately serve a wider range of business operations, or be outsourced to reduce unnecessary incurred cost to the business. The framework techniques are developed and implemented in a consulting CASE tool. The paper is structured as follows; Section 2 discusses the issues of business and IT alignment vs. socio-technical aspects of Information Systems. This section also discusses the complexity of eliciting informal requirements to establish the business and IT alignment. Section 3 describes the adoption of an Organisational Semiotics approach in the consulting framework design to support this. Section 4 describes the Business-Technology Alignment Consulting Framework and three of its techniques, Business Service Analysis, Business Norms and Business Service Valuation for modeling the business landscape through articulating the cultural aspects in an organisation into an explicit form that reflects the business and IT alignment requirements and level. Section 5 draws conclusions and suggests future work. 


\section{Business and IT Alignment from a Socio-technical Viewpoint}

The relationship between business and IT in organisations has a socio-technical aspect that can be viewed via socio-technical theory. Socio-technical theory is a set of explicit concepts that considers the complex interaction of the social aspects, which influence the usability and functionality of technology capabilities [12],[13],[14].The social aspects such as the behavioural patterns of the stakeholders involved are one of the important factors that impact the effectiveness of the technology that supports the business in an organisation [15]. However, the associated mapping and representation of the socio-technical aspects of the organisation is difficult in practice [16],[17], particularly to achieve business and IT alignment.

One approach to achieve business and IT alignment is through enterprise architecture frameworks (EAF) [18],[19] often using service oriented architecture (SOA). The Open Group Architecture Framework (TOGAF), aims to establish a proper alignment between the organisation's business strategy and IT capabilities in a well-structured, comprehensive and systematic manner [20]. Work done in [21] highlights how TOGAF can assist an enterprise to develop a new alignment between business and IT, or improve the existing alignment through the Architecture Development Model (ADM) life cycle. The emergence of SOA concepts has influenced a paradigm shift in business thinking where business components can be viewed as services [22],[23],[24]. Subsequently, these services can be assessed regarding the value they add to the profitability and sustainability of the business. The adoption of SOA in business architecture is beneficial as SOA concepts remove redundancies and align IT infrastructures [25]. The ability to deconstruct business components and organisational structures into sets of services behaving in a service-oriented manner, supports the enhancement of EAF [26]. Yet, the integration of EAF and the SOA concept is not simple as SOA is still considered as an immature technology with no specific foundational theory, and this indirectly complicates the process of defining granular and reusable business and IT services [22]. Work presented in [27],[28], illustrates the integration of EAF and SOA concepts by establishing the linkage of the business services with IT capabilities. However, these approaches focus more on business services than on IT services performance. The availability of information on the IT services performance is crucial to analyse the linkage between business and IT services.

The complexity of alignment is also raised by the fact that the business includes the organisation of people, which cultivates social and cultural informalities. However, accurate inclusion of the socio-cultural factors contributes to the success of the alignment as highlighted in [29],[16],[3],[17]. Work presented in [30] also recognizes the importance to missing non explicit stakeholder social information(s) in modeling enterprise architecture. Lagerstrom et al. [4] address such factors by focusing on stakeholders and their behaviour. However, there is no specific analysis for 1) how stakeholders gain value from their involvement in the business activities and 2) their important views of the value added, or otherwise, by various business services. Cultural aspects have been recognised to fill the informal requirements gap in the business and IT alignment. A study has shown that $30 \%$ of companies have failed in their attempt to achieve business and IT alignment [2]. The main problem highlighted is the miscommunication between business and IT caused by unclear specification of the organisation's business and IT requirements. Business and IT should have a 
well-defined understanding of their own domain within the organisation before proper alignment between them can be successfully achieved. It is often the case that the poor understanding between the business and IT requirements can critically affect the quality of the alignment [31]. Eliciting and representing the business requirements is important for accurate mapping of IT capabilities to obtain the optimal alignment between business service and IT capabilities [32]. Incomplete requirements were also found to be the top reason for failures in the Information System (IS) projects, whereas user involvement was found to have high influence on the IS project success factor [33]. The notion of "completeness" in requirements definition is problematic as there is no specific standard or easy procedure to determine the validity of the requirements information that is important and required by the consultant provided by the users (in our interest, the organisations) [34]. The missing requirements are found to arise from intangible information within the informal (e.g. socio-cultural) factors in the organisation that are difficult to elicit and represent [8],[35]. Incorporating the cultural aspects in the informal requirements is therefore important to fill in gaps in the requirements that forms the foundation for the business [36].

Techniques such as use case development, user centered design. structured interviews and informal modeling, which are among some of the widely practiced approaches by the IT consultant (acting as requirement engineers) [37], are available for eliciting requirements from stakeholders. However, very little attention is given to documentations providing clear understanding and management of the requirements. Well-recorded requirements ensure the identification of any incomplete requirements and enable the realisation of potential reuse of the requirements [38]. One problem identified in the requirement elicitation is the lack of ability to express and record the stakeholders' requirements in an understandable form, for not only the consultants to build the alignment, but also for the non-technical people in the organisation being analysed [39].

\section{Articulation of Complex Business and IT Alignment Requirements}

In an organisation context, business functions are performed within a social system, where people behave in a coordinated manner that corresponds to certain specified norms [40]. Organisational Semiotics (OS) [41],[8] provides a set of elaboration techniques for stakeholder identification and analysis. Treating any technology change, e.g. the introduction of a new IT system, as a course of action, the Stakeholder Identification method aids the analysis by placing the change as the focus of the analysis, which is surrounded by potential stakeholders. The roles, responsibilities and impact of the stakeholders in relation to each course of action can be articulated in a structured manner by careful application of semiotic based stakeholder theory. The application of OS concepts in modeling organisations is supported through a set of tools called Method for Eliciting, Analysing and Specifying Users' Requirements (MEASUR) [42], e.g. problem articulation method (PAM) and norm analysis method (NAM).

PAM provides a set of mechanisms to identify the main issues related to the organisation context, which enables an establishment of understanding of a complex problem situation faced by the business. Valuation Framing serves as a feedback in PAM to 
measure the satisfaction level of the user's needs to the target technical system and is performed iteratively to refine the requirements [41]. The diversity of cultural values among the users influences their perception of the business and IT being measured. Valuation Framing adapted from Hall's [43] ten cultural aspects can provide a basis for capturing and measuring these cultural values. The valuation framing process integrates Hall's metrics with traditional metrics covering quality, performance and providing the organisation with robust information (with added values from cultural aspects) to assist in their decision making process. An Organisational Onion technique facilitates a representation of the stakeholder's relationship to the business function and level of influence in the organisation. Through the definition of the formal, informal and technical factors within the Organisational Onion it addresses the relationships among the stakeholders. It supports the "notion of viewing an organisation as a social system where the people involved internally and externally behaves in a structured patterns that are govern by a certain system of norms" [8].

The norm analysis enables an organisation to study holistically the behaviours of their members and the active interactions between the members that are driven by norms [40]. The norms define the knowledge of the business processes in the structure of $<$ context $>$ followed by the conditions applied in $<$ state $>$ to the associated stakeholders affected or responsible <agent $>$ and to the categorisation of the type of action $<$ deontic operator $>$, and the <action $>$ needed. According to Organisational Semiotics, norms can be categorised into formal and informal. Formal norms are a set of statements, such as business rules governing the business process, which define the expected or intended behavior of the business in an organisation. However, in practice, the stakeholders that are directly involved within the business may develop their own interpretation of the formal norms through adaptation from their cultural background. These informal norms may not be explicitly defined as the behavior of the business and they should not overwrite the formally defined norms. However, these informal norms provide knowledge of the actual social practices that relate to the formal norms of business. Using such knowledge, the organisation will have the capability to implement their strategy and ensure business processes that best fit the working culture, which will eventually improve business performance and productivity.

\section{The Design of the Business-Technology Alignment Consulting Framework}

The consulting framework, as it is developed in collaboration with Capgemini [44], is devised to aid a business and IT alignment. The methods in this framework are underpinned by SOA, TOGAF, PAM, and NAM. The framework consists of a requirements stage; valuation stage; and strategy formulation stage (see Fig. 1). In the first stage, the requirement elicitation for the overall business operations establishes a holistic view of the core and supporting business services. In the second stage, the requirements are analysed to assess the value of the IT applications that support the business services by applying the Valuation Framing techniques [41]. This assessment incorporates an assessment of the financial aspects, (in the IT Financial Analysis component), that influence the value of the IT applications towards the business services. The valuation phase outputs provide information on the state or performance of 
the IT applications in relation to the business services and enables recommendations to optimise the IS/IT performance in the third stage. The consulting framework guides the enterprise to formulate a strategic and flexible IT strategy for improving the business-IT alignment.

The verification of the design was obtained from a group of consultants in the Capgemini consulting team who worked on the actual client case studies. The design of the consulting methods with the techniques has been iteratively refined during the consulting activities.

\subsection{Conceptual Model of the Consulting Framework}

The consulting framework facilitates the analysis of business and IT alignment by a set of techniques as shown in Fig. 1 [44].

Business Domain Analysis analyses the organisations' high level background context, which includes the organisations' business goals and strategy, market and competitive conditions, internal structure, core business services, internal and external main stakeholders and finance flow. The component segments the enterprise's background information into five sections: organisation aspects, business structure, services, external stakeholders and finance. The segmentation is based on Osterwalder's business model [45].

Business Service is where details of the business service including the business processes, the association (if any) of the business services to other business services and the list of the IT applications assigned to support the business services are

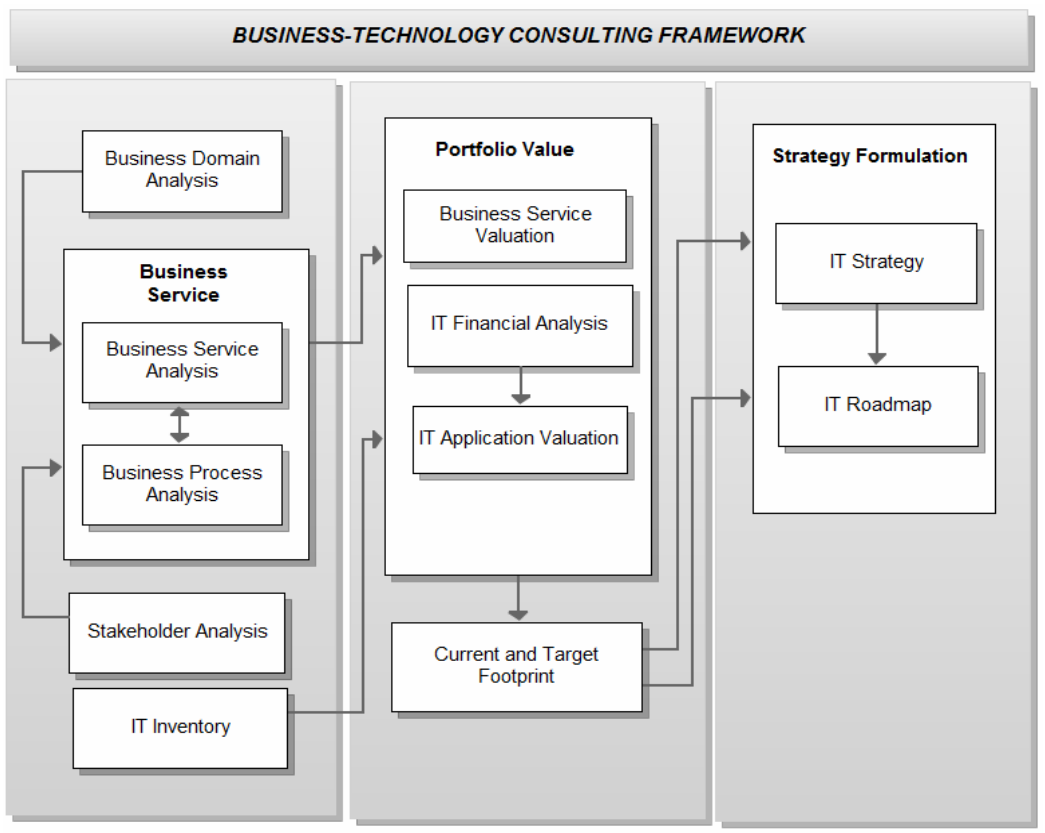

Fig. 1. The Business-Technology Consulting Framework 
extracted. This Analysis captures the informal aspects through the Business Service Norms Analysis, eliciting the organisation's business norms within the business processes that support the business services. To complement the analysis in achieving the holistic view of the business service, its cultural value is evaluated in Business Service Valuation. The analysis will be presented and discussed in detail in the following section.

Business Process Analysis provides detailed descriptions of processes/subprocesses and activities involved in the business services. The business processes are influenced by, and are tightly integrated with, business norms. The business service norms analysis captures the behaviour patterns as requirements enabling us to derive the business rules from both the business and customer focused perspective. It also identifies the informal factors involved in the business service, such as strategies, cultures, unwritten conventions and common practices supporting the business capability. The analysis extends the details of the business rules and procedures with knowledge of any pre-conditions and post-condition from the Business Process Analysis.

Stakeholder Analysis is the component where the detailed analysis and elicitation of requirements of the associated stakeholders of the business service is performed. Stakeholder Analysis enables the identification and evaluation of highly influential stakeholders and their influence on business services in the enterprise, refining the stakeholder information identified in the business service analysis. Stakeholders perceive different values for the business services according to their perspectives. The stakeholder valuation of the business service is one of the important factors in the Business Service Analysis.

IT Inventory is the IT applications requirements analysis, where detailed information concerning the IT applications assigned to support the business services are elicited. The IT Application Inventory analyses all the IT applications in the enterprise to provide a foundation for further valuation assessment. The inventory component is divided into: 1) current IT applications (as-is state); and 2) recommendation for future changes to IT applications (to-be state). In the as-is state, each IT application available within the enterprise is recorded and described in detail: its capabilities, financial cost and technical value. The IT application value is evaluated in a separate component in the second stage, IT Application Valuation whereas, in the to-be state, the inventory includes recommendations for decisions to be made for the status of each IT applications (e.g. to be outsource, upgrade to improve performance, merge with other applications etc). The comprehensive requirements from both the business processes and services and IT applications form the basis for the components in the next stage, the Strategy Formulation to formulate future IT strategy that improves the business-IT alignment.

\subsection{The Application of Business Services Analysis}

Fig. 2 presents a case study to illustrate the framework. Techniotics ${ }^{\mathrm{TM}}$ is an advanced systems development company operating in three markets: advanced intelligent systems, defence electronics and robotics, alternative energy systems. It has global presence and market capitalisation and the following core competences: 1) highly skilled and rewarded, networked and virtual workforce; 2) patented processes for advanced 
electronics and autonomous systems manufacture; 3) extensive range of patents and intellectual property in the three sectors; 4) rapid design to manufacture virtual processes; and 5) innovative knowledge focused on new product development processes.

In the analysis process, we focus on a Techniotics ${ }^{\mathrm{TM}}$ example core competency: the innovative knowledge focused new product development processes. This is provided by Techniotics ${ }^{\mathrm{TM}}$ 's unique range of engineers and scientists and marketing staff that form the core product concept teams, supported by global part-time problem solving consultants connected as virtual team members to the company and the extensive supporting IT systems. The key service is Product Conceptualisation. This internal service delivers an output: to identify three product concepts using the marketing departments' concept market specification that has been developed from an external client request for a new product/service. Product Conceptualisation is part of their New Product Development service that comprises several sub-services. The service operates according to a set of business rules or norms and is subject to constraints from business strategy, marketing and compliance. The set of business norms also have related social implications and social norms. For example a business norm specifies the internal company teams' tasks. This satisfies business norms that ensure for example, satisfaction with the task and support of the social contract that the key stakeholder value.

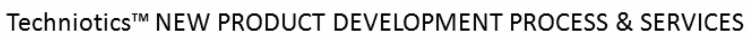

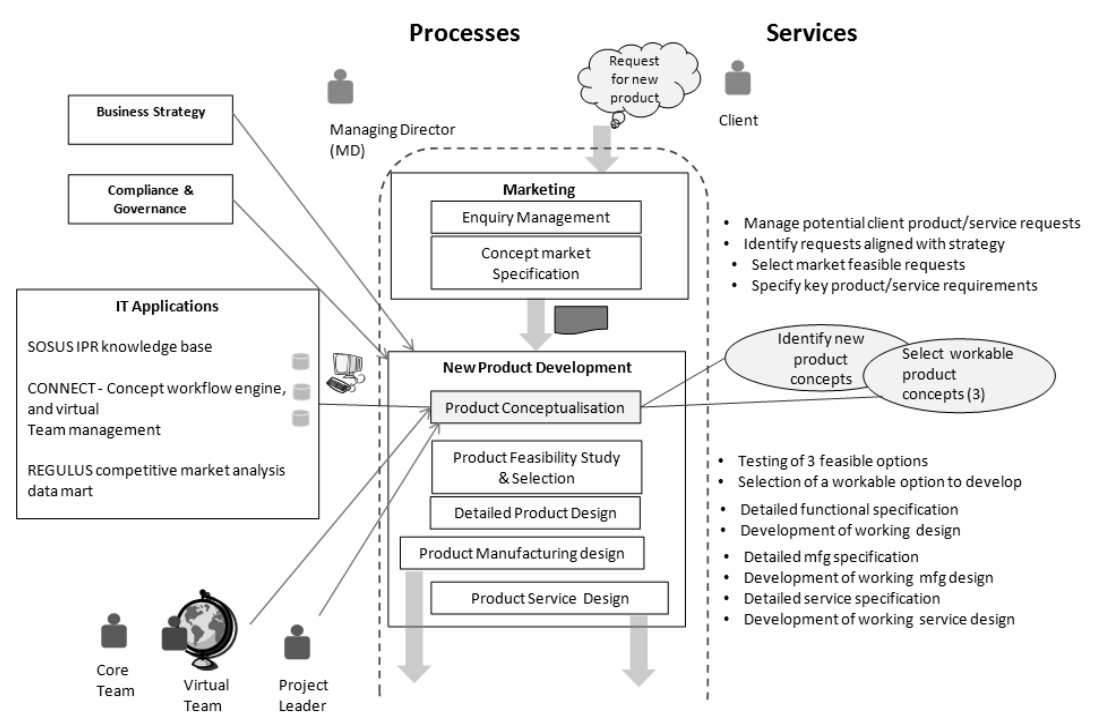

Fig. 2. Overview of Techniotics ${ }^{\mathrm{TM}}$ example business processes, services and IT applications

\subsection{Business Service Analysis for the Alignment}

Business Service Analysis in Fig. 3 assesses each business service which is defined by Business Domain Analysis with regard to their capabilities, stakeholder's participation in the business process, and IT applications support. In the business service 
analysis, a number of further techniques (see the shaded elements in Fig. 3), e.g. business cultural valuation, stakeholders analysis, definition of service norms, and business process modeling, IT Inventory, IT Application Valuation are applied and the corresponding outcomes recorded in this document.

\begin{tabular}{|c|c|c|c|c|c|}
\hline \multicolumn{6}{|c|}{ BUSINESS SERVICE ANALYSIS } \\
\hline \multirow[t]{3}{*}{ Service name: } & \multirow[t]{3}{*}{ Product Conceptualisation } & ID: & \multirow{3}{*}{$72 \%$} & \multirow{3}{*}{\begin{tabular}{|l|} 
Type: \\
Date:
\end{tabular}} & \multirow{3}{*}{\begin{tabular}{|l|} 
Core / Support \\
$29 / 04 / 2010$
\end{tabular}} \\
\hline & & Business Cultural & & & \\
\hline & & Value: & & & \\
\hline Description: & \multicolumn{5}{|c|}{$\begin{array}{l}\text { Identify three new product concepts based on product design norms that could proceed to feasibility study } \\
\text { stage of new product development }\end{array}$} \\
\hline Stakeholders: & \multicolumn{5}{|c|}{ Marketing team, Core team, Virtual team, Project leader, Managing Director, Client } \\
\hline Service Norms: & \multicolumn{5}{|c|}{ PCStart1001, PCldentify1002, PCOptimize1003, PCApproval1004 } \\
\hline Business Process: & \multicolumn{5}{|c|}{$\begin{array}{l}\text { 1) Project Leader received concept market specification from marketing team. 2) Core and Virtual team } \\
\text { identify/generates new product concepts that fits the business strategy for approval by MD . 3) Virtual team } \\
\text { assess workable product concepts to satisfy cost analysis and risk management criteria. 4) Core and Virtual } \\
\text { team optimizes the best three concepts for approval by the project leader to proceed to the next stage: } \\
\text { Product Feasibility Study\& Selection }\end{array}$} \\
\hline Process Models: & \multicolumn{5}{|c|}{ P47: Product conceptualisation - as is v0.5 } \\
\hline \multicolumn{6}{|l|}{ Relationships } \\
\hline part-of: & \multicolumn{5}{|l|}{ New product development } \\
\hline shared with: & \multicolumn{5}{|l|}{ Marketing } \\
\hline input/output: & \multicolumn{5}{|c|}{$\begin{array}{l}\text { inputs: concept market specification. } \\
\text { Outputs: } 3 \text { approved product concept }\end{array}$} \\
\hline joint outcomes: & \multicolumn{5}{|c|}{ potential solution designs approved for Service-Product Feasibility Study \& Selection (ID: S2.2) } \\
\hline IT applications: & SOSUS IPR, CONNECT, REGULUS & II Application val & ue to Business & Service: & $73 \%$ \\
\hline
\end{tabular}

Fig. 3. The analysis of business service requirements

The business service of Product Conceptualisation is a core service, which identifies new product concepts based on ideas from the clients. This business service can be described with service name, ID, description, date, and list of associated stakeholders, which are further analysed in detail by using the Stakeholder Analysis. The business behavior is described in P47 in conjunction with the service norms. Product Conceptualisation carries out its function in relation to other business services, e.g. it jointly produces the outcomes with Service-Product Feasibility Study \& Selection.

Product Conceptualisation is supported by a list of IT applications, i.e. SOSUS, CONNECT, and REGULUS, each of which is detailed in the IT Inventory. Its value to this business service is calculated in the example as $73 \%$ by the IT Application Valuation. This value implies that the IT applications that the organisation has invested in, gives a good ROI in terms of its support of the functions in the business service. The requirements documented in this structure are used as the input for the subsequent analysis in the consulting process.

\subsection{Norms for Governing the Business Behaviour}

A norm is considered as a control mechanism for the business to deliver its value to customers through the business services. These business services are performed by the stakeholders whose behavior impacts on the business output. The consulting framework identifies two types of norms, i.e. service norms and social norms, which 
may govern the business services. Service norms as formal norms define a business context (i.e. business service) where the activities are conducted by the stakeholders through the business processes. Fig. 4 presents the service norms which govern the business behavior of Product Conceptualisation. Each norm focuses on the specific expected behavior of Product Conceptualisation. For example, PCIdentify1002 defines that the proposed new product concepts can only be accepted by the MD if they satisfy the business strategy.

\begin{tabular}{|c|c|c|c|c|c|}
\hline Business Service ID: & S2.1-NPD-PC & & & & \\
\hline Rule ID & $\begin{array}{r}\text { Whenever } \\
\text { <context> }\end{array}$ & $\begin{array}{l}\text { if } \\
\text { state> }\end{array}$ & $\begin{array}{c}\text { then } \\
\text { sagent }\end{array}$ & $\begin{array}{c}\text { is } \\
\text { <deontic operator> }\end{array}$ & $\begin{array}{c}\text { to } \\
\text { saction> }\end{array}$ \\
\hline PCStart1001 & $\begin{array}{l}\text { concept market specification is } \\
\text { received }\end{array}$ & $\begin{array}{l}\text { specification is } \\
\text { complete and stable }\end{array}$ & $\begin{array}{l}\text { Core Team and } \\
\text { Virtual Team }\end{array}$ & obliged & $\begin{array}{l}\text { confirmed acceptance by Project } \\
\text { Leader. }\end{array}$ \\
\hline PCIdentify 1002 & $\begin{array}{l}\text { New product concepts are } \\
\text { identified }\end{array}$ & $\begin{array}{l}\text { each concepts fits } \\
\text { business strategy }\end{array}$ & MD & obliged & proceed to optimization process. \\
\hline PCAssess1003 & Pre-selected concepts exist & $\begin{array}{l}\text { concepts satisfy the } \\
\text { cost analysis and risk } \\
\text { management criteria }\end{array}$ & Virtual Team & obliged & optimized 3 product concepts. \\
\hline PCApproval1004 & $\begin{array}{l}3 \text { product concepts has been } \\
\text { optimized }\end{array}$ & $\begin{array}{l}\text { product concept is to } \\
\text { be approved }\end{array}$ & Project Leader & obliged & $\begin{array}{l}\text { approve the product concepts report } \\
\text { for Product Feasibility Study \& } \\
\text { Selection }\end{array}$ \\
\hline
\end{tabular}

Fig. 4. Description of the business norms that govern the business processes

Social norms as informal norms are implicit and not formally codified. These norms are used by individuals and groups to execute the actual behavior (vs the codified behaviour). Social norms need to be identified to appreciate the stakeholders' rights and interest in the business activities and the related technology. It is important to take these factors into consideration as stakeholders are the influential aspects in determining the value of the business activities and IT support. In the consulting framework, the social norms are derived from the Hall's ten cultural aspects which characterise some quantified measurements. The social norms in the consulting analysis are applied to evaluate business cultural value in a Business Service.

\subsection{Evaluate the Cultural Values of Business Services}

During the Product Conceptualisation analysis, the business cultural value needs to be assessed. Such cultural values should be taken into account in the business service analysis as this can provide a more truthful view of any lack of alignment, or forced perceived alignment due to political/social pressure affecting an individual's value judgment. In conducting a valuation, the Business Service Valuation is used in Fig. 5.

In the valuation matrix, the relevant stakeholders and criteria are also weighted accordingly to its degree of significance on the business service. The weighting schema or values for both are not fixed and can be adjusted to suit the objective of the consultancy exercise, provided the total weighting of all involved stakeholders in the business service and the overall criteria sums to 1 respectively. The stakeholders then rate each of the criteria based on the value range -3 to +3 . In the valuation of Product Conceptualisation, six stakeholders have been identified and weighted. These stakeholders rated the business services and first, the overall value of the business service cultural value per stakeholder is calculated by $V S_{i}$. Then, the value is recalculated 


\begin{tabular}{|c|c|c|c|c|c|c|c|}
\hline Business Service ID: & S2.1 -NPD-PC & & & & & & \\
\hline \multirow[t]{2}{*}{ Stakeholder (Si) } & & $\begin{array}{l}\text { Marketing } \\
\text { Team }\end{array}$ & $\begin{array}{l}\text { Core } \\
\text { Team }\end{array}$ & $\begin{array}{l}\text { Virtual } \\
\text { Team } \\
\end{array}$ & $\begin{array}{l}\text { Managing } \\
\text { Director }\end{array}$ & $\begin{array}{l}\text { Project } \\
\text { Leader }\end{array}$ & Client \\
\hline & Stakeholder weight & 0.10 & 0.25 & 0.25 & 0.10 & 0.10 & 0.20 \\
\hline Criteria & Criteria weight & & & & & & \\
\hline Core competence & 0.2 & 2 & 3 & 2 & 3 & 2 & 3 \\
\hline Knowledge/skill specialisation & 0.05 & 2 & 2 & 2 & 2 & 3 & -1 \\
\hline Learning capability & 0.05 & 1 & 2 & 1 & -1 & 2 & -2 \\
\hline Task satisfaction & 0.04 & 1 & 1 & 2 & -1 & 2 & -1 \\
\hline Social contract & 0.01 & 1 & 1 & 1 & 1 & 1 & -2 \\
\hline Adaptability & 0.05 & 1 & 1 & 2 & 2 & 2 & 1 \\
\hline Interaction & 0.1 & 2 & 2 & 2 & 3 & 3 & 3 \\
\hline Transparency & 0.1 & 2 & 2 & 2 & 3 & 3 & 3 \\
\hline Operational risk & 0.03 & 2 & 2 & 3 & 2 & 2 & 1 \\
\hline Environment risk & 0.02 & -1 & 1 & 2 & 2 & 2 & 1 \\
\hline Reputation risk & 0.02 & 3 & 3 & 1 & 3 & 2 & 1 \\
\hline Security risk & 0.03 & 1 & 2 & 1 & 3 & 2 & 1 \\
\hline Service productivity & 0.02 & 1 & 2 & 2 & 3 & 3 & 3 \\
\hline Quality-timeliness & 0 & 2 & 1 & 3 & 2 & 3 & 3 \\
\hline Quality-Output: General Product/service & 0.1 & 2 & 3 & 2 & 3 & 3 & 3 \\
\hline Financial benefit & 0.1 & 2 & 3 & 3 & 3 & 3 & 3 \\
\hline Reliability/consistency & 0 & -1 & 1 & 3 & 3 & 3 & 3 \\
\hline Cultural benefit & 0 & 1 & -2 & -3 & -3 & -2 & -1 \\
\hline Customer benefit & 0.04 & 2 & 2 & 2 & 2 & 2 & 3 \\
\hline Sustainability & 0 & 1 & 2 & 1 & 2 & 2 & 2 \\
\hline \multirow[t]{3}{*}{ Information security } & 0.04 & 1 & 2 & 2 & 3 & 3 & 3 \\
\hline & $\begin{array}{l}\text { VSi }=\text { Sum(Stakeholder } \\
\text { rate * service criteria } \\
\text { weight) }\end{array}$ & 1.72 & 2.30 & 2.02 & 2.43 & 2.50 & 2.04 \\
\hline & $\begin{array}{l}V=V S i * \text { Stakeholder } \\
\text { weight }\end{array}$ & 0.17 & 0.58 & 0.505 & 0.243 & 0.25 & 0.408 \\
\hline Total Business Service cultural value: & \multicolumn{6}{|l|}{$\operatorname{Sum}(V) / 3$} & $72 \%$ \\
\hline
\end{tabular}

Fig. 5. The culture values perceived by the relevant stakeholders

with consideration of the stakeholders weight to provide the values according to the strength of their influences on the business service in $V$. The final value of $72 \%$ is then calculated by $\operatorname{Sum}(V) / 3$ which provides a percentage value of the business cultural value according to the overall perceptions of the stakeholders involved. This cultural value indicates the positive perception of Product Conceptualisation by the stakeholders.

The business service analysis needs to be conducted on all business services in Techniotics ${ }^{\mathrm{TM}}$ to establish a holistic view of the business. As the framework requires a full spectrum of quantitative and qualitative analysis supporting alignment, the technical aspects (i.e. IT) in the organisation need to be thoroughly analysed by using Portfolio Value analysis which analyses the financial aspects and risk management. The outcomes of this analysis assists the formulation of IT strategies for Techniotics $^{\mathrm{TM}}$, i.e. what IT applications should be invested in the future, what IT applications should be considered for outsourcing etc. A socially informed IT strategy can help organisations make the right decisions for IT applications based on the business and IT alignment. 


\section{Conclusion}

The design of the consulting methodology has been discussed, focusing on the Business Service Analysis component and its close relationship with the Business Service Norms Analysis which provides a structured approach to elicit the social (cultural) aspect values embedded in the business. The articulation of the social values helps to provide a more complete and holistic representation of the business services in the organisation. We have, using the example, shown how to identify the business norms provided by the analysis methods and techniques. We have also addressed the need to include the cultural aspects that impact the business and IT alignment. Although the social aspect is considered as implicit knowledge, it can have a significant influence on the business service values and IT applications that support the business services.

The holistic representation from the business service analysis is complemented by the Business Service Valuation in the Portfolio Valuation where the emphasis is on determining the cultural values of the business service. The analysis is performed by capturing the organisation stakeholders' perception of the business services and IT applications. The outcome of the complete valuation phase enhances the holistic view of their business-IT alignment presented in the Business Service Analysis and contributes to the other analysis components, specifically the Strategy Formulation component, where a future IT strategy and a roadmap for an improved alignment can be developed for the organisation.

Future work will focus on the development of a complete consulting methodology. This will include a validation of the architecture using actual organisations. This is critical to test the framework against real business issues to ensure the validity of the methodology for practical use. Further development to complete the consulting methodology toolset is also under construction.

\section{References}

1. Chan, Y.E., Reich, B.H.: IT alignment: what have we learned? Journal of Information Technology 22, 297-315 (2007)

2. Tallon, P.: The Alignment Paradox. CIO Insight (2003), http: //www.cioinsight.com/c/a/Past-News / Paul-Tallon-TheAlignment-Paradox/

3. Campbell, B.: Alignment: Resolving ambiguity within bounded choices. In: Pacific Asia Conference on Information Systems, Bangkok, Thailand (2005)

4. Lagerström, R., et al.: Enterprise Meta Modelling Methods - Combining a StakeholderOriented and A Causality-Based Approach. In: 13th International Workshop on Exploring Modelling Methods in Systems Analysis and Design 2009, Amsterdam, The Netherlands (2009)

5. Gartner: Gartner Says Worldwide IT Spending On Pace to Surpass $\$ 3.4$ Trillion in 2008 (2008), http: / / www .gartner.com/it/page.j.sp?id=742913

6. Gartner: Gartner Says Worldwide IT Spending to Grow 5.3 Percent in 2010 (2010), http: / / www.gartner.com/it/page.jsp?id=1339013

7. Luftman, J., Kempaiah, R., Rigoni, E.H.: Key Issues for IT Executives 2008. MIS Quarterly Executive 8(3), 151-159 (2008) 
8. Liu, K.: Semiotics in Information Systems Engineering. Cambridge University Press, Cambridge (2000)

9. Ulrich, W., McWhorter, N.: Defining Requirements for a Business Architecture Standard, B.A.S.I.G. Technical Report, The OMG (2010)

10. Versteeg, G., Bouwman, H.: Business architecture: A new paradigm to relate business strategy to ICT. Information Systems Frontiers 8(2), 91-102 (2006)

11. Luftman, J., Brier, T.: Achieving and Sustaining Business-IT Alignment. California Management Review 42(1), 109-122 (1999)

12. Trist, E.L., Bamforth, K.W.: Some Social and Psychological Consequences of the Longwall Method of Coal-Getting. Human Relations 4(1), 3-38 (1951)

13. Baxter, G., Sommerville, I.: Socio-technical systems: From design methods to systems engineering. Interacting with Computers, Corrected Proof (2008) (in press, Corrected Proof)

14. Walker, G.H., et al.: A review of sociotechnical systems theory: a classic concept for new command and control paradigms. Theoretical Issues in Ergonomics Science 9(6), 479-499 (2008)

15. Mumford, E.: A Socio-Technical Approach to Systems Design. Requirements Engineering 5(2), 125-133 (2000)

16. Chan, Y.E.: Why Haven't We Mastered Alignment? The Importance of the Informal Organization Structure. MIS Quarterly Executive 1(2), 97-112 (2002)

17. Zacarias, M., et al.: Adding a Human Perspective to Enterprise Architectures. In: Wagner, R., Revell, N., Pernul, G. (eds.) DEXA 2007. LNCS, vol. 4653, pp. 840-844. Springer, Heidelberg (2007)

18. Zachman, J.: A framework for information systems architecture. IBM Systems Journal 26(3), 276-292 (1987)

19. Jonkers, H., et al.: Concepts for Modeling Enterprise Architectures. International Journal of Cooperative Information Systems 13(3), 257-287 (2004)

20. TOGAF: TOGAF version 9 Enterprise Edition. The Open Group Architecture Framework, TOGAF (2009)

21. Buckl, S., et al.: Using Enterprise Architecture Management Patterns to Complement TOGAF. In: IEEE International on Enterprise Distributed Object Computing Conference, EDOC (2009)

22. Brahe, S.: BPM on Top of SOA: Experiences from the Financial Industry. Business Process Management 96-111 (2007)

23. Hagel Iii, J., Singer, M.: Unbundling the Corporation. Harvard Business Review 77(2), 133-141 (1999)

24. Iansiti, M., Levien, R.: The Keystone Advantage. Harvard Business School Press, Boston (2004)

25. Erl, T.: SOA: Principles of Service Design. The Prentice Hall Service-Oriented Computing Series from Thomas Erl. Prentice Hall/PearsonPTR (2008)

26. Bieberstein, et al.: Impact of service-oriented architecture on enterprise systems, organizational structures, and individuals. International Business Machines 44(18) (2005)

27. Orriens, B., Yang, J., Papazoglou, M.P.: A Rule Driven Approach for Developing Adaptive Service Oriented Business Collaboration. In: Benatallah, B., Casati, F., Traverso, P. (eds.) ICSOC 2005. LNCS, vol. 3826, pp. 61-72. Springer, Heidelberg (2005)

28. Cherbakov, L., et al.: Impact of service orientation at the business level. IBM Syst. J. 44(4), 653-668 (2005)

29. Reich, B.H., Benbasat, I.: Factors that Influence the Social Dimension of Alignment between Business and Information Technology Objectives. MIS Quarterly 24(1), 81-113 (2000) 
30. Kilpeläinen, T.: From Genre-based Ontologies to Business Information Architecture Descriptions. In: 17th Australasian Conference on Information Systems, Adelaide, Australia (2006)

31. Luftman, J., Papp, R., Brier, T.: Enablers and inhibitors of business-IT alignment. Commun. AIS, 1(3es) (1999)

32. Grant, K., Hackney, R., Edgar, D.: Strategic Information Systems Management. Thomas Rennie (2010)

33. Hull, E., Jackson, K., Dick, J.: Requirements Engineering. Springer, Heidelberg (2005)

34. Kotonya, G., Sommerville, I.: Viewpoints for requirements definition. Software Engineering Journal 7(6), 375-387 (1992)

35. Liu, K., Sun, L., Tan, S.: Modelling complex systems for project planning: a semiotics motivated method. International Journal of General Systems 35(3), 313-327 (2006)

36. Coughlan, J., Macredie, R.D.: Effective Communication in Requirements Elicitation: A Comparison of Methodologies. Requirements Engineering 7(2), 47-60 (2002)

37. Neill, C.J., Laplante, P.A.: Requirements engineering: the state of the practice. IEEE Software 20(6), 40-45 (2003)

38. Samuel, R., et al.: A pattern-based method for building requirements documents in callfor-tender processes. Technical Report. Technomathematics Research Foundation (2009)

39. Toro, A.D., et al.: A Requirements Elicitation Approach Based in Templates and Patterns. In: WER 1999, pp. 17-29 (1999)

40. Stamper, R., et al.: Understanding the Roles of Signs and Norms in Organisations. Journal of Behaviour and Information Technology 19(1), 15-27 (2000)

41. Stamper, R.K.: Knowledge as action: a loci of social norms and individual affordances. Social Action and Artificial Intelligence (1985)

42. Stamper, R., et al.: Signs plus norms - one paradigm for organisation semiotics. In: The First International Workshop on Computational Semiotics, Paris, France (1997)

43. Hall, E.T.: The Silent Language. Doubleday and Company, New York (1959)

44. CEAR: Business Aligned IT Strategy (BAITS) - Methodology and User Guide. Capgemini Enterprise Architecture Research (2009)

45. Osterwalder, A.: The Business Model Ontology - a proposition in a design science approach. In: Institu d'Informatique et Organisation. University of Lausanne, Lausanne (2004) 